NBER WORKING PAPER SERIES

\title{
CASH WELFARE AS A CONSUMPTION \\ SMOOTHING MECHANISM FOR \\ SINGLE MOTHERS
}

Jonathan Gruber

Working Paper 5738

\section{NATIONAL BUREAU OF ECONOMIC RESEARCH 1050 Massachusetts Avenue \\ Cambridge, MA 02138 \\ September 1996}

I am grateful to Raaj Chitaley for expert assistance in creating the PSID database, to Becky Blank, Janet Currie, Bruce Meyer, Robert Moffitt, Aaron Yelowitz, seminar participants at the University of Wisconsin and the NBER, and particularly Hilary Hoynes for helpful comments, and to the National Institute on Aging for financial support. This paper is part of NBER's research programs in Labor Studies and Public Economics. Any opinions expressed are those of the author and not those of the National Bureau of Economic Research.

(C) 1996 by Jonathan Gruber. All rights reserved. Short sections of text, not to exceed two paragraphs, may be quoted without explicit permission provided that full credit, including $\mathbb{C}$ notice, is given to the source. 
NBER Working Paper 5738

September 1996

\title{
CASH WELFARE AS A CONSUMPTION \\ SMOOTHING MECHANISM FOR \\ SINGLE MOTHERS
}

\begin{abstract}
While there has been considerable research on the disincentive effects of cash welfare under the Aid to Families with Dependent Children (AFDC) program, there is little evidence on the benefits of the program for single mothers and their children. One potential benefit of this program is that it provides short-run consumption insurance for women at the point that they become single mothers. This is only true, however, to the extent that the program is not crowding out other sources of support, such as own savings, labor supply, or transfers from others. I assess the importance of this insurance mechanism by measuring the extent to which AFDC smooths the consumption of women who transition to single motherhood. I use longitudinal data on family structure and consumption expenditures on food and housing from the Panel Study of Income Dynamics (PSID), matched to information on the welfare benefits available in each state and year over the 1968-1985 period. I find that raising potential benefits by one dollar raises the food and housing consumption of all women who become single mothers (and their families) by 30 cents. This estimate implies that for each dollar of AFDC received by this population their consumption of these categories of goods rises by up to 95 cents. This consumption smoothing benefit appears to be larger for women who become single mothers through marital dissolution, rather than through out-of-wedlock childbearing; this is due to increased housing expenditures of the former group but not of the latter.
\end{abstract}

Jonathan Gruber

Department of Economics

Room E52-274c

Massachusetts Institute of Technology

Cambridge, MA 02139

and NBER

gruberj@athena.mit.edu 
One of the most extensively debated government expenditure programs of the past few years has been the provision of cash welfare to single mothers and their children under the Aid to Families with Dependent Children (AFDC) program. Despite absorbing only $1 \%$ of government expenditures, ${ }^{1}$ this program has been roundly criticized because of the perceived distortions arising from the structure of program incentives. In particular, since AFDC is both means tested and (for the most part) categorically restricted to single mothers, critics have claimed that the program leads to both reductions in work effort and dissolution of the family unit. While empirical evidence on these questions is very mixed, they remain compelling criticisms in theory and have motivated calls for reform, and perhaps even abolition (Murray, 1984), of our cash welfare system.

At the same time, the key benefit of this program is that it transfers resources to a presumably quite needy population. Proponents of AFDC have therefore painted proposals to reduce the generosity of this program as potentially devastating to single mothers and their children. However, these types of arguments presume that reductions in AFDC benefits are not compensated by increases in support from other sources. In fact, as critics such as Charles Murray (1984) and Marvin Olasky (1992) have noted, in the absence of this cash transfer program other mechanisms might respond to maintain the standard of living of single female headed families. Such mechanisms could include self-insurance through savings and through own or family labor supply, transfers from family members of cash or in-kind benefits, or transfers from other charitable institutions. If there are private market or non-market mechanisms which are being "crowded out" by the current welfare system, then the implications of reductions in AFDC generosity for the standard of living of single female-headed families is unclear. But while the disincentive effects of AFDC have been subject to

${ }^{1}$ In 1992 , AFDC expenditures were $\$ 22.2$ billion, slightly more than $1 \%$ of combined Federal and State and Local expenditures of $\$ 2100$ billion (U.S. House of Representatives, 1993; Economic Report of the President, 1994). 
extensive empirical testing and criticism, there is very little evidence to support or refute the benefits that this program has in terms of raising the standard of living of recipients.

It is impossible to know what types of institutions might emerge to support single mothers and their children in the absence of any cash welfare system, so that one cannot estimate the effect of eliminating AFDC on the standard of living of this population. ${ }^{2}$ In this paper, I pursue a more modest goal: to explore the role of the existing cash welfare system as a consumption smoothing device for women at the point that they become single mothers. Divorce or out-of-wedlock childbearing is potentially associated with a large reduction in the standard of living of these women and their families. One goal of the welfare system, as with other social insurance programs such as unemployment insurance, is to insure family income against this adverse event. ${ }^{3}$ To the extent that AFDC provides such insurance, it represents a benefit of the program which must be weighed against any distortions that arise from the structure of this means-tested categorical transfer.

I assess the extent to which AFDC provides this insurance by exploiting the tremendous variation in the generosity of this program across states, and within states over time. If cash welfare is playing such a consumption smoothing role, there should be corresponding variation in the consumption change for those becoming single mothers in different states and times. That is, to the extent that AFDC is not simply crowding out other sources of support, then increases in benefit

${ }^{2}$ One potential empirical strategy for answering this question would be to use historical evidence on insurance arrangements before the growth of the AFDC program. For example, Olasky (1992) argues that private charity provided an effective safety net for the indigent before the emergence of the New Deal. But, even to the extent that this is true, underlying changes in the nature of the economy and private insurance mechanisms over the subsequent years make it difficult to extend this conclusion to the removal of the current social safety net.

${ }^{3}$ At the same time, of course, critics claim that cash welfare is causing these transitions to single motherhood; I address this important point at length below. For a related argument and evidence for the unemployment insurance system, see Gruber (forthcoming). 
levels should be translated directly to smaller (per capita) consumption reductions associated with becoming a single mother.

My primary source of data for this analysis is the Panel Study of Income Dynamics (PSID). This longitudinal survey allows one to follow women as they move between marital and childbearing states. I use two different measures of consumption that are available in the PSID: food expenditures and housing expenditures. The PSID data are matched to information about the welfare system in each state over the 1968-1985 period to estimate the basic consumption smoothing relationship.

To summarize, I find that the transition to single motherhood is associated with only a small $3 \%$ reduction in food and housing expenditures on average. However, this small reduction is due to the important consumption smoothing role played by AFDC. For the full sample, each dollar of AFDC eligibility mitigates the consumption fall associated with single motherhood by 30 cents. That is, the reduction in consumption from this adverse event would be over seven times as large if AFDC were not available. I also find that for each dollar of AFDC received by those becoming single mothers is associated with (at most) a 95 cent rise in consumption of food and housing. This result suggests that there is not a significant crowdout of other sources of support by the AFDC system. This consumption smoothing effect operates for both women who become divorced and those single women who have children, although the effect is larger on the former group, primarily through the effect of AFDC on housing expenditures.

The paper proceeds as follows. In Part I, I provide background on the welfare system and related research, and a simple model to illustrate the potential for AFDC to serve as a consumption smoothing mechanism. Part II describes the data, and Part III discusses the empirical strategy. Part IV then presents the basic PSID regression results, and pursues a number of specification checks and extensions. Part V concludes. 


\section{Part I: Welfare and Consumption Smoothing}

\section{Background on AFDC}

AFDC is the largest cash welfare program for the able-bodied non-elderly in the U.S.4 Benefits under the AFDC program have been traditionally limited to single mothers who meet relatively restrictive income criteria; on average across the states in 1987, AFDC eligibility was limited to those below $60 \%$ of the poverty line. But there has also been tremendous variation across the states in the generosity of their AFDC programs, as well as substantial differences within states over time. In 1968 , the average state had AFDC benefits of $\$ 1971$ for a family of three, but this varied from a low of $\$ 546$ (Mississippi) to a high of $\$ 3875$ (New Jersey). Over the next 16 years (the period covered by my PSID sample), nominal benefits grew by an average of $111 \%$, but this growth ranged from a low of $29 \%$ (Illinois) to a high of $416 \%$ (Alaska). ${ }^{5}$ In real terms, benefits fell by $31 \%$ over this period; real benefit growth varied from $-58 \%$ to $67 \%$.

States also have the option of covering married couples as well, if the head is under-employed (working less than 100 hours per month), under the AFDC-UP program. This program has traditionally been quite small, however. In 1970 , only $4 \%$ of families on AFDC were enrolled through this option; this share had grown to only $7 \%$ by 1985 , the last year of my sample (U.S. House of Representatives, 1993). Thus, for the purposes of this analysis I will treat AFDC eligibility as being restricted to single mothers.

\footnotetext{
${ }^{4}$ The SSI program, which provides benefits to the poor disabled and elderly, is of roughly the same magnitude as the AFDC program. Additional cash welfare is provided by some state General Assistance programs. I will only focus on cash welfare through AFDC in this paper, although when I measure welfare income receipt in the PSID I will include all welfare income, since the distinction in the survey between AFDC and other welfare may not be a clear one.

${ }^{5}$ Alaska is an outlier in terms of positive benefit growth; for the next highest state, growth was $258 \%$ (Maine). Even using this figure, the disparity in benefit growth is substantial, with a 10-fold difference in growth rates across states.
} 
There is an enormous literature which has focused on the effects of cash welfare on behavior; see Moffitt (1992) for a comprehensive review. There are two common features to almost all previous research in this area. First, the identification strategy generally relies on variation in the generosity of cash welfare across states and time. Second, in almost every case the focus of the research has been on the disincentive effects of AFDC. All of the articles reviewed by Moffitt focus on the potentially deleterious effects of the AFDC program for labor supply, marital status, childbearing, long term welfare dependence, or migration. But there is little work on the benefits of the program for the targeted group, single mothers.

There is a large body of older research which attempts to assess the adequacy of AFDC, in terms of raising recipients out of poverty; see Danziger et al. (1981) for a review. But, as Danziger et al. emphasize, this literature has all been static; that is, none of these studies have allowed for any offsetting income flows in response to increases in AFDC generosity. To the extent that any offsetting behavioral responses to the program exist, these calculations overstate the effects of AFDC on the standard of living of single mothers. But there has been little attempt to incorporate these responses in measuring the extent to which increases in AFDC generosity translate to an improved standard of living.

In theory, the adequacy of AFDC could be assessed by using evidence from these previous studies on how other sources of support for single mothers are reduced, or crowded out, when welfare becomes more generous. But the list of potential sources of support is a very long one, and there is only evidence on some of these margins. For example, there is some evidence that changes in the AFDC guarantee reduce labor supply (see the evidence reviewed in Danziger et al. , 1981). ${ }^{6}$

${ }^{6}$ Moffitt (1986) provides more recent evidence, and the results are mixed once state fixed effects are included in the model. 
But the evidence on the crowdout effect on transfers from others is mixed, ${ }^{7}$ and there is no work on the response of savings behavior. ${ }^{8}$

In addition, there is substantial anecdotal and personal interview evidence that AFDC recipients are maintaining their living standards by relying on legal and illegal income sources that are not reported to the AFDC caseworker and presumably not reported to the (PSID or other) survey interviewer either (Edin, 1995). But no previous research has assessed how these unreported sources of income respond to AFDC generosity changes, and it is difficult to imagine doing so giving the inherent data problems. Finally, there is no work on how these different margins interact; the response of private transfers to AFDC generosity may be a function of how labor supply responds, for example. Thus, an alternative approach must be used to answer this question. The approach proposed in this paper is to directly examine how AFDC generosity differences are translated into changes in the standard of living for women who transition to single motherhood.

\section{A Model}

In order to lay out the nature of the expected relationship between AFDC and consumption changes, it is useful to write down a simple model of the consumption implications of the transition to single motherhood. The unit of observation, which I label the "welfare unit", is a woman and her (zero or more) children, who faces some risk of becoming a single mother either through divorce (in the case where she is married, and there are some children already present), or through

\footnotetext{
${ }^{7}$ Rosenzweig and Wolpin (1994) find only a small crowdout effect of AFDC on parental contributions to young women. Cox and Jacubson (1995) find a crowdout of the probability of receiving support, but not the amount of support. Scheoni (1994) finds a larger crowdout for blacks.

${ }^{8}$ Powers (1996) does find that asset limits under the AFDC program appear to affect asset accumulation levels, but she does not explore the role of benefits variation.
} 
childbearing (in the case where she is unmarried, and there are not yet children present). In the first period of the model, the welfare unit has earned income of $y$ available with which to finance the consumption of the women and her children. ${ }^{9}$ The woman can also set aside some of this income, s, for savings, either in the form of financial assets or loans to others that can be drawn down at some later date. ${ }^{10}$ She faces a risk of $(1-\alpha)$ of becoming a single mother in period 2 ; this is assumed to be exogenous, a point to which I return in the empirical work. If she becomes a single mother, the net income of the welfare unit falls to $k y$, where $0<k<1$; this is either because the husband leaves (in the case of dissolution), or because the woman either cannot work or must hire child care (in the case of child-bearing). On the other hand, in this case the woman has three additional resources with which to finance consumption: her own savings (s), AFDC payments (A), or transfers from others $(t)$. Transfers from others are gifts, consisting of some lump sum amount, and also (potentially) of some amount which is a general function of her net income in the single mother state:

$$
t=T+f(k y+A)
$$

Following the details of the current AFDC program, benefits are the maximum AFDC payment (A) minus a $100 \%$ tax rate on other income. However, I assume that transfers from others are not reported to the AFDC authorities; nor do the authorities measure the "savings" that the woman has

\footnotetext{
${ }^{9}$ The amount y can be viewed as the outcome of a within-family bargaining process which yields some division of consumption between the welfare unit and other household members. An important limitation of the PSID data in practice is that I only observe total family consumption in the data and not the consumption of the welfare unit alone; I discuss this issue in more detail below.

${ }^{10}$ For example, groups of women who face a high risk of single motherhood may make loans to their friends when they become single mothers. These are different than the transfers modelled below, which are not "balanced budget" but are simply gifts to the single mother.
} 
available. ${ }^{11}$ Thus, AFDC benefits are:

$$
\mathbf{A}=\mathbf{A}-\mathbf{k y}-\mathbf{s}
$$

If she doesn't become a single mother, the woman consumes her savings, but receives no AFDC or transfers from others. Thus, the woman maximizes the two period utility function:

$$
U=U[y-s]-1 /(1+\delta)\left[\alpha^{*} U\left[y+s^{*}(1+r)\right]+(1-\alpha)^{*} U\left[k y+s^{*}(1+r)+A+t\right]\right.
$$

where $\delta$ is her discount rate and $\mathbf{r}$ is the rate of return on savings.

This model can be solved for the change in consumption upon single motherhood, as a function of the AFDC guarantee $\underline{A}$. To provide illustrative results, I solve the case where $\delta=r=0$, where utility is of the log form, and where previous income is normalized to one. The results of this exercise are depicted in Figure 1. The AFDC maximum payment is displayed along the $\mathrm{x}$ axis, and the change in consumption is measured on the $y$ axis. I consider the case where $\alpha=0.95$ ( 5 percent chance of becoming a single mother), and $k=0$ (no earned income for the welfare unit after the transition to single motherhood), for four different scenarios: transfers which are a lump sum set to be $20 \%$ of pre-dissolution income, but which are not a function of AFDC benefits, and no savings; savings with lump sum transfers; savings, and transfers which offset one-half of net AFDC payments; savings, and transfers which exactly offset AFDC payments.

In the first case, with no savings and no transfers, there is a one-for-one consumption smoothing role of AFDC; that is, since there is no source of private insurance, each dollar of public insurance is translated directly to consumption. In fact, in this case, if AFDC replaces more than $80 \%$ of pre-dissolution income there is an increase in consumption due to the fixed transfer. In each

${ }^{11}$ This is consistent with the evidence in Edin (1995). Making transfers "taxable" by the AFDC system would not qualitatively change the conclusions of the model. Similarly, I do not condition transfers on the mother's savings; this does not change the qualitative conclusions, since these are two different margins of crowdout. 
of the other cases, however, the consumption smoothing effect of AFDC is smaller. Introducing savings, but excluding transfers, mitigates the consumption smoothing role of AFDC substantially for low AFDC benefits, since there is negative infinite utility at zero consumption; as AFDC benefits rise, savings crowds out a smaller share of benefits, since the marginal utility of consumption in the second period is sufficiently high. Introducing transfers further increases the crowd out of AFDC (and of savings); in the limit, with fully offsetting transfers, there is no consumption smoothing effect.

Thus, only in the limiting case of no savings and no transfers from others will increases in AFDC benefits be directly translated to consumption; in other cases, some of the benefit increase will crowd out private insurance mechanisms. The ultimate extent of consumption smoothing is an empirical question. This model suggests the empirical formulation of that question as a regression of the change in consumption upon single motherhood on the amount of AFDC benefits available; this is the approach that I pursue below.

\section{Related Work}

There are two previous papers that directly assess the welfare gains from increases in AFDC generosity. Currie and Cole (1993) examine the effect of changes in AFDC generosity on the health of infants born to AFDC recipients; they find no correlation between AFDC payment levels and infant health. A previous attempt to measure the consumption effects of AFDC is Pollack (1994). He also uses the PSID data to model the consumption of AFDC recipients as a function of state/year AFDC generosity, for the $1981-1987$ period. He finds that a $10 \%$ increase in program generosity raises the food consumption of AFDC recipients by roughly $7 \%$. This is a suggestive finding, but his approach suffers from three problems. First, while empirical estimates of most behavioral effects 
of AFDC are in general inconclusive, the one response which has been documented most clearly is that AFDC participation does respond to AFDC generosity (see the evidence reviewed in Moffitt, 1992; also Moffitt, 1986). This leads to a potential sample selection bias in the estimates, if the women who select into this sample as AFDC becomes more generous have differential consumption patterns. Second, an important consideration in this type of regression is the fact that AFDC benefit changes are potentially correlated with state-level changes in the cost of living over time, and thus with consumption expenditures. This is not surmounted by the inclusion of state effects of even individual fixed effects, since there may be low frequency movements in prices within areas which drive both consumption expenditures and AFDC benefits over time. Finally, one problem with using PSID data for this type of analysis in the past has been the fact that subfamilies (in which roughly $1 / 2$ of single mothers reside) have not been identified in the data; I present an approach to surmounting this problem below.

\section{Part II: Data}

The primary data set for this analysis is the PSID. This longitudinal survey has been carried out continuously since 1968, following the same sample of families and their "split-offs" over time. The original sample consisted of a nationally representative cross-section and a sub-sample of families in poverty; in the analysis below I use both samples in order to increase the precision of the estimates.

The PSID is the only multi-year longitudinal data set available with information on consumption behavior. Each year, respondents are asked how much their family "usually" spends on food at home and food away from home, as well as the amount of food paid for by food stamps. 
They are also asked about expenditures on rent and mortgage payments. ${ }^{12}$ I deflate each component of consumption by the CPI for that component in the month of the interview, and then sum the real components (including food stamps). I also exclude observations where any element of consumption is imputed, rather than reported directly by the respondent. It is unfortunate that broader consumption aggregates are not available in the PSID, forcing me to limit myself to food and housing expenditures. These are, however, the types of necessary expenditures that are of most interest for those concerned about the well-being of single mothers and their families. ${ }^{13}$

There are at least three potentially important data issues with using the PSID sample. The first is timing. The rent and mortgage questions clearly refer to the point of the PSID interview. Although the frame of reference for the food consumption measures is not entirely clear, Zeldes (1989) convincingly argues that it refers to the point of the interview (rather than the previous year). ${ }^{14}$ This timing matches the information on family structure, which is recorded at the point if the interview as well. However, it does not match the information on welfare receipt, which is from the previous calendar year. This will introduce measurement error in a regression of consumption on welfare income, a problem to which I return below.

\footnotetext{
${ }^{12}$ Food consumption data are missing for 1973; mortgage payment data are missing for 19731975. But I am able to use some data for 1974 and 1975 by noting that mortgage payments are zero for renters. The PSID also gathers information on expenditures on utilities, but these data are missing for several additional years so I did not use them in the analysis.

${ }^{13}$ I have attempted to replicate this analysis using the Consumer Expenditure Survey (CEX), which provides information on all consumption expenditures for the 1980 to 1993 period. Unfortunately, there were sufficiently few transitions to single motherhood (roughly 220) in those data that I was unable to estimate the response to AFDC with any precision. For those transitions, food and housing expenditures were roughly $40 \%$ of total non-durable expenditures in the period preceding single motherhood.

${ }^{14}$ One exception is food expenditures paid for using food stamps. Before 1977, this is measured using average food stamp expenditure last year; from 1977 onwards, food stamp expenditure in the month of the survey is used.
} 
Second, an important limitation of the PSID for this type of analysis is the difficulty in identifying relationships among sample members. The data set identifies clearly the household in which each sample member lives, as well as their relationship to the household head. It also identifies subfamilies that moved into existing PSID households. Thus, for nuclear households (father, mother, and own children under 18), or for new subfamilies (ie. divorced daughters with children who move back into their parents' home), it is easy to identify family relationships. But for other types of non-nuclear households, containing related or unrelated subfamilies, it is much more difficult to identify welfare-eligible family units, and to track women over time as they become single mothers. For this reason, for example, Hoynes (1995) defines single motherhood as single household headship, except for those women who move out of their parents homes and then back in. This follows most other work on family structure using the PSID. This is clearly a major limitation, since much of the policy interest in AFDC focuses on women who are in subfamilies.

Moffitt and Rendall (1993) suggest a means of surmounting this problem for the period 19681985 by using the PSID "Relationship File". This file provides pairwise information on the relationships between all members of the PSID sample, using detailed fertility and marital histories. This allows one to construct welfare-eligible family units from the raw data, and to follow women over time as their family structure changes. The basic strategy suggested by Moffitt and Rendall is to search over all children in the PSID and assign them to a mother, which I do with varying degrees of accuracy; this allows me to state whether women are mothers regardless of whether they are identified family heads or not. I then use the marital history information to assign marital status, completing the measure of single mothership.

Third, consumption in the PSID is measured at the family level, and the event of interest for this study by necessity changes the composition of the family, thereby changing underlying 
consumption needs. For example, family consumption will by definition fall when there is a divorce and the husband moves out of the household. In other words, due to the sampling frame of the PSID there is a form of built in "state dependence" in consumption changes: women who become single mothers may see a change in their measured family consumption even if their per capita living standards don't change. ${ }^{15}$

Ideally, this problem would be surmounted by measuring the consumption of the welfare unit only, but these data are not available in the PSID. I therefore deal with this problem in three ways in the empirical analysis. First, I include detailed controls in the regression models for the level of and the change in family composition. These controls should help to pick up any change in the underlying demand for consumption from changes in family structure. Second, in one extensions below, I measure the change in consumption of the entire original family, and not just of the welfare unit; that is, for a woman who moves out of her parents house, I measure the aggregate change in the consumption of her plus her parents. This allows me to maintain the same underlying composition of the consumption unit across interviews. Of course, to the extent that there are economies of scale in consumption which aren't captured by my composition controls, then measured expenditures will change when households split even if the underlying consumption is the same, limiting the advantages of this approach. Therefore, as a third approach, I focus on the results for wives who divorce and become family heads. This population all has a similar shock: they are losing the consumption of a husband. Thus, by restricting to this sample, the constant picks up the effect of composition change, and the AFDC coefficient picks up the consumption smoothing for the

\footnotetext{
${ }^{15}$ If changes in household composition were independent of AFDC benefit levels, then this would bias the estimate of the average change in consumption from single motherhood, but not the marginal impact of AFDC. In fact, however, there is evidence that women move into independent residences as AFDC is more generous (Ellwood and Bane, 1985).
} 
mother and her children.

The sample consists of all 14-64 year old women who become single mothers between one interview and the next. Women can make this transition for one of two reasons: marital dissolution or out-of-wedlock childbearing. ${ }^{16}$ They can then become either clearly identified family heads or live in unidentified subfamilies; this distinction is important because consumption is measured at the family level, so the effects of AFDC on family consumption will be clearest in the cases where the family consists of the welfare-eligible unit only. $44 \%$ of the transitions in my sample are due to marital dissolution, and $56 \%$ to childbearing. Almost all of the women who get divorced are clearly identified family heads, while almost all of those who have children out of wedlock live in unidentified subfamilies. The fact that roughly one-half of the women in my sample are not family heads highlights the importance of including sub-families in the analysis, using the Moffitt and Rendall methodology.

An important consideration in selecting my sample, of course, is that becoming a single mother may be a function of the generosity of the welfare system. If the types of women who transition to single motherhood as benefits rise have disproportionately high consumption, it could bias towards a spurious consumption smoothing finding. The extent to which this bias exists is a direct function of the effect of welfare generosity on single motherhood. Evidence on this front is mixed, as reviewed by Moffitt (1992). Early studies found no effect of AFDC on divorce or childbearing probabilities, while more recent cross-sectional analyses have begun to find some effects. But once state fixed effects are included in these models, as they are in the regressions below, any effects of welfare on single motherhood disappear (Moffitt, 1994; Hoynes, 1995). This

\footnotetext{
${ }^{16}$ I will refer interchangeably to marital dissolution and divorce. There may be some dissolutions in my sample which are due to the death of the husband, but I do not distinguish these from other types. In my age range there should be relatively few dissolutions due to death.
} 
suggests that there is no potential for sample selection bias in the sample of single mothers. I explicitly test for sample selection below.

\section{Part III: Empirical Strategy}

\section{Reduced Form}

I begin by running reduced form regressions in the PSID of the form:

$$
\Delta \mathrm{C}_{\mathrm{ijk}}=\alpha+\beta_{1} \mathrm{MAX}_{\mathrm{ij}}+\beta_{2} \mathrm{X}_{\mathrm{ijk}}+\beta_{3} \mathrm{Z}_{\mathrm{jk}}+\beta_{4} \delta_{\mathrm{j}}+\beta_{5} \tau_{\mathrm{t}}+\beta_{6} \delta_{\mathrm{j}}^{*} \text { TREND }+\epsilon_{\mathrm{ijk}}
$$

where $\Delta \mathrm{C}_{\mathrm{ij}, \mathrm{j}}$ is the real change in consumption for family $\mathrm{i}$ in state $\mathrm{j}$ in year $\mathrm{t}$

MAX $_{\text {ir }}$ is the real maximum AFDC payment level

$X_{i, k}$ is a set of family-specific control variables

$Z_{\mathrm{j}}$ is a set of state/year-specific control variables

$\delta_{\mathrm{j}}$ is a full set of fixed state effects

$\tau_{1}$ is a full set of fixed time effects

TREND is a linear time trend

In this specification, I model the effect of potential AFDC benefits (the maximum benefit entitlement) on the consumption change of women who become single mothers (between periods t- 1 and t) and their families. By using consumption changes, I potentially avoid an important limitation of cross-sectional regressions in this context: AFDC benefits may be set as a function of the cost of living in the state, which is also correlated with consumption expenditures. Even with state effects included in the regression, changes in prices within a state will induce a spurious positive correlation between benefits and consumption levels. But, by differencing out consumption from the previous period, I am able to control for short-run price differences across areas. That is, instead of requiring no correlation between AFDC benefits and price levels, I impose the weaker assumption that there is no correlation between AFDC benefits and price changes. This most likely surmounts any problems that arise from my inability to control for area-specific food and housing costs.

While this assumption is considerably weaker, there remains the possibility that omitted 
state/year factors affect both AFDC benefits setting and consumption changes within a state. I therefore pursue two additional steps to ensure that this assumption is warranted. First, in addition to a set of state fixed effects, I include a full set of state-specific trends. This will capture any longterm within-state correlated shifts in consumption patterns and AFDC benefit generosity. Second, I include two state/year control variables that will help to absorb any general correlation between AFDC benefit-setting and the nature of consumption opportunities in a state and year: the unemployment rate and the log of personal income per capita.

Despite my use of consumption changes, I use the level of potential AFDC benefits as the key regressor. This is because for this population, their potential AFDC benefits are zero by definition in period $t-1 .{ }^{17}$ So using levels is the same as using changes here, since the lagged level of benefits is zero.

The regression also controls for a set of individual demographic characteristics: race, own age, the age of the family head (who may or may not be the woman, depending on the sample), and the education of the family head. The key regressor is the maximum AFDC benefits for which a family is eligible, based on the state and year, and on the size of the AFDC family unit. I also include dummies for the size of the AFDC family unit and the total PSID family size in the regression, to ensure that there is not spurious identification from the fact that larger families are eligible for a larger AFDC benefit. ${ }^{18}$ Similarly, I include dummies for the change in family size,

\footnotetext{
${ }^{17}$ In practice, some of the women in the treatment group will have received AFDC in period $\mathrm{t}-1$, due to the problems of data timing that $I$ have discussed.

${ }^{18}$ These two concepts differ only for those in subfamilies. An alternative approach to avoid identification from family size would be to use the benefits for a fixed family size in each state and year. Using benefits for a family size of three yields a similar coefficient estimate to that reported below, but the standard error is approximately $50 \%$ larger, reflecting the reduced variation in the independent variable.
} 
to control for the fact that a husband is leaving or a child is added, thus the total consumption needs of the PSID family may change. ${ }^{19}$ I also include the change in the family's "food needs", which is a variable constructed by the PSID to reflect not only family size but the age of family members as well. Finally, I include an indicator for whether this transition to single motherhood was caused by marital dissolution or by childbearing, since there may be quite different changes in underlying food needs from these different events; I separate the analysis into these two subgroups below. ${ }^{20}$

\section{Benefits Receipt}

The regression (1) -answers the question: if you make single female heads eligible for one more dollar of welfare receipt, what happens to their consumption? A different question that could be asked is: for each dollar of welfare received by single female heads, what happens to their consumption? Eligibility does not translate directly to receipt, for two reasons. First, there is much less than full takeup of AFDC benefits; Blank and Ruggles (1992) estimate that takeup is only about 2/3. Second, not all single heads are eligible for the maximum benefit level; in particular, there is a tax rate on income after some deductions that has varied from $66 \%$ to $100 \%$ over the sample period.

On the other hand, this receipt question cannot be answered by a direct regression of consumption changes on welfare benefits received. As discussed earlier, takeup of welfare is

\footnotetext{
${ }^{19}$ That is, I include dummies for each of the following categories: no change in family size; an increase of one person, 2 persons, 3 persons, or 4 or more persons; and a decrease of one person, 2 persons, 3 persons, or 4 or more persons.

${ }^{20}$ Note that I do not include controls for changes in other family resources, besides AFDC; by the crowdout argument detailed earlier, these are endogenous to the generosity of AFDC. In a specification check below, I do include lagged values of family resources as controls to capture any heterogeneity in ex-ante circumstances correlated with AFDC benefits.
} 
endogenous, leading to a potential sample selection bias to the estimates. Furthermore, there is considerable measurement error in information on AFDC benefits received, both due to the usual reporting problems and the fact that in the PSID the timing of the consumption data is different than the timing of the welfare receipt data. There is a natural instrumental variable for benefits received, however: the maximum benefit amount. The maximum benefit entitlement is clearly correlated with benefits received, and the working hypothesis of this paper is that maximum benefits is uncorrelated with consumption changes other than through the effects of the welfare system. Thus, by instrumenting welfare received by maximum benefits, I solve the problems with reduced form estimation of the second stage equation.

That is, I run a system of equations of the form:

$$
\begin{gathered}
\text { WELF }_{\mathrm{ijh}}=\sigma+\delta_{1} \mathrm{MAX}_{\mathrm{ijh}}+\delta_{2} \mathrm{X}_{\mathrm{ij}}+\delta_{3} \mathrm{Z}_{\mathrm{jt}}+\delta_{4} \delta_{\mathrm{j}}+\delta_{5} \tau_{\mathrm{t}}+\delta_{6} \delta_{\mathrm{j}}^{*} \text { TREND }+\epsilon_{\mathrm{ijt}} \\
\Delta \mathrm{C}_{\mathrm{ijt}}=\alpha+\tau_{1} \mathrm{WELF}_{\mathrm{ijt}}+\tau_{2} \mathrm{X}_{\mathrm{ijt}}+\tau_{3} \mathrm{Z}_{\mathrm{jt}}+\tau_{4} \delta_{\mathrm{j}}+\tau_{5} \tau_{\mathrm{t}}+\tau_{6} \delta_{\mathrm{j}}^{*} \text { TREND }+\eta_{\mathrm{ijt}}
\end{gathered}
$$

where WELF is the amount of welfare income received by family $i$ and the other variables are defined above. Estimating this system by Two-Stage Least Squares yields the parameter coefficient of interest, $\tau_{1}$, which is the effect of receiving another dollar of welfare on the consumption change.

Both the reduced form parameter from equation (1) $\left(\beta_{1}\right)$ and the $2 S L S$ parameter from equation (2) $\left(\tau_{1}\right)$ are of interest. The former is most directly policy relevant, as argued by Gruber (1994). Government policy-makers cannot directly control AFDC receipt, but they can control the level of potential benefits. So $\beta_{1}$ measures the relationship of direct policy interest, which is the effect of raising welfare generosity on consumption of the potentially eligible population. The latter allows one to assess how consumption responds directly to income received. That is, if we are to understand the extent to which other sources of support are crowded out by AFDC, we need to model how much consumption rises for each dollar of AFDC receipt. 
An important limitation of the 2SLS estimate $\tau_{1}$, however, is that it might overstate the effect of AFDC on consumption. This is because there may be some option value of the program even for those single heads that don't take up benefits. Suppose that there is some fixed cost to taking up AFDC benefits; a clear example here would be stigma associated with receipt of cash welfare (Moffitt, 1983). This is consistent with there being less than full takeup among those eligible for the program. Consider a new single mother who would prefer not to take up stigmatizing welfare, but who is unsure of her prospects for finding other sources of income. She may delay takeup while she sorts out her financial situation. But in the meantime she will account for the presence of insurance through AFDC in her consumption choices; that is, she will consume more today than she would if this contingent option were not available, since she knows that she can go on the AFDC program if necessary. In this case, $\tau_{1}$ will reflect the effect of benefits variation on both recipients and non-recipients, leading to a likely upward bias to the estimate for recipients only. The sign and magnitude of this bias are explored further in the Appendix.

In theory, this problem could be surmounted if there was a second instrument which could be used to model selection into takeup of AFDC. I was unable to find such an instrument, however. It is worth noting that this is a general problem with the literature on AFDC and other social insurance programs; analysts either estimate the reduced form or 2SLS coefficients, but are unable to measure precisely the option value of these programs on those who do not take them up.

\section{Means}

Before exploring the consumption smoothing role of AFDC, it is first useful to ask: given the existence of AFDC, what are the average consumption implications of becoming a single mother? Evidence on this question is provided in the first column of Table 1. The second column provides 
the consumption changes for the control group, as a basis for comparison. The first number in each cell is the mean change, and the second number is the standard deviation; the number in curly brackets is the lagged mean value. All dollar figures are in real 1984 dollars.

Combining food and housing expenditures, there is a reduction of $\$ 184$ when the woman becomes a single mother. This is only $3.1 \%$ of the baseline value of consumption of these goods. ${ }^{21}$ For food, the drop is a larger 5.6\% fall. But housing expenditures actually rise somewhat, reflecting the fact that some women are moving to new residences; the rate of moving is roughly $50 \%$ higher in the sample of women becoming single mothers than for the control group. The overall consumption change for the control group is roughly zero, reflecting a commensurate small decline in food consumption and rise in housing consumption.

The means of the remaining PSID covariates are presented in Table 1 as well. Women who become single heads are disproportionately minorities, and they are in families whose heads have low educational attainment. These facts partially reflect the oversampling of disadvantaged households in the PSID; note that even for the control group over $30 \%$ are black. ${ }^{22}$ The non-zero welfare receipt information for families which do not contain a single mother at periods t or $\mathrm{t}-1$ may reflect some transitions within the year that are not captured by my point in time household status measures, or welfare received during the calendar year of interview $t-1$ but before the point of the interview itself (which is sometime in the spring). It may also reflect receipt of other welfare under state general assistance plans or the AFDC-UP program.

\footnotetext{
${ }^{21}$ Of course, this figure is not corrected for scale economies and is therefore somewhat misleading, since family composition is changing for the single mothers. This is controlled for in the regressions below.

${ }^{22}$ When the sample weights are used to account for this, the key variables (consumption and AFDC benefits entitlement) are not much changed, but the sample appears much less disadvantaged along observable dimensions (for both the treatments and the controls).
} 


\section{Part IV: Results}

\section{Basic Results}

Table 2 reports the basic reduced form regression results. I present results for food and housing expenditures combined, and then for the two categories separately.

For total food and housing expenditure, there is a sizeable and significant positive coefficient on maximum AFDC payments. For every dollar in potential benefits, the consumption fall associated with single motherhood is mitigated by 30 cents. This implies that at the mean potential benefits for the sample, consumption among this population is increased by $\$ 1170$, relative to the absence of cash welfare benefits. This result is reflected in the next to last row, which shows the implied consumption fall upon single motherhood for the (out of sample) case of a zero maximum potential benefit. In that case, the consumption fall upon single motherhood would be $\$ 1353$, or more than seven times as large as the consumption fall given our current system (from Table 1). This represents almost $23 \%$ of baseline consumption for this population. So this regression shows that the small consumption change that we observe for women becoming single mothers is largely due to the generosity of our current cash welfare system; in the absence of this system the consumption fall would be substantial. The remaining coefficients in the regression are uniformly insignificant, except for the change in family consumption needs.

Dividing the dependent variable into food and housing expenditures, we see that AFDC has a positive and (marginally) significant effect in each case. The effect on food is about $50 \%$ larger, but the two coefficients are statistically indistinguishable. The results imply that in the absence of AFDC food consumption would fall by roughly $23 \%$ of its baseline value when women became single mothers, and housing expenditure would fall by roughly $22 \%$. So, within each category, AFDC is playing an important consumption smoothing role. 
The final row of the Table presents the 2SLS estimates of the effect of a dollar of benefits receipt on consumption. Recall that this is an upper bound estimate of the extent to which a dollar of benefits received is translated to consumption spending. This upper bound estimate is 95 cents for total consumption; that is, one cannot reject the hypothesis that each dollar of AFDC received is translated to a dollar of increased food and housing expenditure. Of this 95 cents, roughly 56 cents comes from increased spending on food and 39 cents from increased spending on housing, although these two $2 S L S$ coefficients are not very precisely estimated.

Thus, the basic results indicate that AFDC is playing a very important consumption smoothing role for those becoming single mothers, through both food and housing expenditures. Moreover, the results suggest that there is not an important crowdout effect of AFDC on other sources of support. Of course, to the extent that there is an option value of the program for nonrecipients, this is an upper bound estimate, so that if the option value is large there may be a substantial crowdout. Also, given the fact that we only have data on only $40 \%$ of the consumption bundle for these women, we cannot precisely infer crowdout here. nevertheless, the results are suggestive of a small degree of crowdout.

\section{Other Transfer Programs}

One potential problem with the empirical work thus far is that I have used as my key regressor cash welfare benefits only. In fact, single mothers are also eligible for other government assistance as well. One important example is food stamps. The exclusion of the value of food stamps leads to a downward bias to my consumption smoothing estimates, since benefits are conditioned on income, including AFDC. This means that by there is an automatic crowdout of food stamps by increases in AFDC, so that when food stamps are accounted for the estimate of 
consumption smoothing will rise even further.

Unfortunately, it is difficult to appropriately account for the effects of in-kind programs, since to combine their influence with that of AFDC would require a cash equivalent of their value. For the case of food stamps, however, a number of studies suggest that Food Stamps benefits are roughly equivalent to cash transfers of the same value (ie. Moffitt, 1989), so that many previous papers on the behavioral effects of the welfare system simply combine food stamp and AFDC entitlements to get the overall effect of both programs. ${ }^{23}$ I do the same in the first panel of Table 3, taking account of the fact that food stamp benefits are reduced by a fraction of AFDC benefits, after some deductions. ${ }^{24}$ As expected, the estimated coefficients are somewhat larger when the combined maximum is used. The reduced form coefficient now implies a 46 cent increase in consumption for each dollar of AFDC benefits, and the 2SLS coefficient now exceeds one. ${ }^{25}$ The precision of the estimates has been reduced, however, so that one cannot reject that they are the same as those using the cash welfare maximum alone.

The other two major public assistance programs for single mothers are public housing and health insurance through the Medicaid program. Accounting for the effect of these benefits is much

\footnotetext{
${ }^{23}$ Fraker et al. (1995) review a number of studies which suggest that food stamps may be worth somewhat less than a cash equivalent, but even in these cases the value is quite close ( 72 to 82 cents of cash for each dollar of food stamps). Moreover, if food stamps distort consumption towards food, this would further exacerbate the downward bias to my non-food stamps estimate for food consumption (since food stamps are included in my food consumption measure).

${ }^{24}$ Specifically, food stamp benefits are reduced by 30 cents for each dollar of income above and beyond a standard deduction and deductions for shelter expenses and child care expenses.

${ }^{25}$ Note that for the 2 SLS coefficient the dependent variable is non-food stamp consumption, and the independent variable in the second stage is welfare income received plus consumption paid for by food stamps.
} 
harder, since there is little consensus on their cash-equivalent value. ${ }^{26}$ A further difficulty with public housing, relative to food stamps, is that there is only a limited amount of housing assistance available, so that one must account for the probability that the family actually receives help. Given these problems, I do not attempt to account for the programs in the analysis. Since public housing benefits also "tax" income received from AFDC, the argument above implies that I would only increase my estimate if I accounted for the program, unless there are state specific differences in public housing programs which are positively correlated with AFDC. ${ }^{27}$ For Medicaid, the net bias from omitting program changes is harder to predict. Given the uniformity of most features of the program, it is unlikely that there is a strong correlation between the AFDC maximum and the value of Medicaid benefits. On the other hand, increases in AFDC benefits, in general, raise the income cutoff for Medicaid eligibility, which would raise the value of the program on average for single women. $^{28}$

\footnotetext{
${ }^{26}$ See, for example, Smeeding and Moon (1980), Wolfe and Moffitt (1991), and Manser (1992) for the case of Medicaid; and Olsen and Barton (1983), Reeder (1985), and Schwab (1985) for the case of public housing. One methodology used in some studies of Medicaid is to add average state/year Medicaid expenditures per recipient to the food stamp plus AFDC benefit to get a combined benefit total. But, given the uniformity of the Medicaid benefit structure across states, average state/year expenditures largely reflect differences in population characteristics and price differences, not insurance value.

${ }^{27}$ Also, the housing expenditure variable does not include the value of public housing. So if subsidies distort consumption towards housing, this will lead to an offsetting bias against finding consumption smoothing if I exclude potential public housing benefits (since increases in AFDC lower public housing benefits, raising expenditure on non-public housing).

${ }^{28}$ Another important consideration with Medicaid is that, beginning in the mid-1980s, the link between AFDC and Medicaid was severed by a series of expansions of the Medicaid program to traditional family structures and higher income levels (Currie and Gruber, 1996a,b). This could confound the analysis, if Medicaid were available both before and after the transition to single motherhood. However, these expansions had not started by the time that my PSID sample ends in 1985.
} 


\section{Specification Checks}

The empirical results presented in Tables 2 are predicated on a key identification assumption: that the underlying consumption tastes or needs of women who become single mothers in places with more or less generous AFDC benefits are the same. In this section, I provide a number of tests to assess the validity of this assumption.

One means of assessing the identification assumption is to control further for potential underlying differences in the population of single mothers. I do so in the first row of Table 4 by including a set of lagged individual and family characteristics: lagged values for family income, the earnings of family head, the earnings of the woman (who may in some cases have been labelled by the PSID the family head), and her hours of work. As the second panel of Table 3 shows, including these extra controls has little effect on the results.

An alternative reason why AFDC may be spuriously correlated with consumption changes is that I have not fully conditioned out the underlying correlation between AFDC benefits setting and changes in consumption opportunities. I can assess the validity of this criticism by rerunning the regression for a within-state control group: those who remain married or who remain unmarried nonheads from interview $t-1$ to $t$. For these populations, there should be little effect of AFDC on consumption changes. ${ }^{29}$ But if there is a spurious correlation between AFDC benefits setting and consumption opportunities, it should be reflected in the consumption of women who don't become

\footnotetext{
${ }^{29}$ There may be effects through long run behavior of those women who perceive some risk of relying on AFDC. For example, as noted in the model above, these women may save less on their own if AFDC is more generous, leading to faster consumption growth rates for the family. There may also be effects on their labor supply and job choice. But all of these effects should be quite small for the average married couple, given the low odds that a given married woman will end up on AFDC. There also may be some small positive effects because some of these women may have been single heads during the year (as illustrated by the non-zero welfare income for this control group).
} 
single mothers as well.

In fact, as the final panel of Table 3 shows, there is only a very small positive effect of AFDC benefits on the consumption change of this population. Thus, there does not appear to be important omitted correlates of both AFDC benefits setting and changes in consumption opportunities.

Finally, one reason why the identifying assumption may be violated is sample section bias arising from women becoming single mothers in response to changes in AFDC generosity. Sample selection bias to the estimates would require both that AFDC induce more women to become single mothers, and that those women who are induced by AFDC have different underlying consumption needs or tastes that are not captured by my set of controls. However, the first of these requirements is refuted by the previous literature on AFDC which finds that, once state effects are included in the regression, there is no effect of welfare on single motherhood (Hoynes, 1995; Moffitt, 1994).

To make this point more clearly for my sample, I re-estimate models of the effect of AFDC on the transition to single motherhood. That is, I estimate regressions of the form of (1), but where the dependent variable is now a dummy for becoming a single mother, and the sample is both women who do and do not become single mothers. There are two regressions: one for transitioning to single motherhood through marital dissolution (from married mother to single mother); and one for transitioning to single motherhood through childbearing (from unmarried childless woman to single mother). ${ }^{30}$

\footnotetext{
${ }^{30}$ For these regressions, I exclude the controls for family size and food needs (but retain controls for size of the welfare unit), since these are clearly endogenous to whether the transition to single motherhood is made. I also control only for the woman's age, and not for the head's age as well, since the difference between these ages will be a function of whether the woman is a single mother (since single mothers are often heads). The coefficient estimate of interest is not sensitive to either of these changes in the regression specification.
} 
The results of these probit regressions are shown in Table 4. For both types of transitions, the coefficient on AFDC benefits is insignificant, which is consistent with previous work; for transition through child-bearing, the coefficient is even wrong-signed. The third row from the bottom of each column is the implied marginal probability of a $\$ 1000$ increase in AFDC benefits on the likelihood of being a single mother. Even in the first column, where the coefficient is positive, the implied effect of this large benefits increase is only $3 \%$ of the mean likelihood of having a transition. Moreover, taking a weighted average of these two coefficients for the full sample of single mothers, the estimated effect is negative. The implication is that these data support the contention from other studies that AFDC is not an important determinant of single motherhood in models that include state effects.

\section{Extension: Types of Consumption}

Table 5 extends the analysis by further dividing the food and housing consumption measures. I first divide the food consumption variable into food consumed at home and food consumed away from home. To the extent that AFDC generosity increases have their expenditure effects by simply inducing a shift from restaurant to home consumption, it suggests that expenditure changes may overstate changes in nutritional value, which might be the underlying measure of most interest from a social welfare perspective. In this case, we would expect that increases in AFDC generosity are reflected mostly in food consumed away from home; in fact, it is possible that the coefficient on food at home could be negative. But we observe the reverse in Table 5: there is no effect of AFDC on food away from home, and a large effect on food at.home. While this doesn't allow one to definitively convert these estimates to nutritional values, it does reduce the concern over the result being driven by a shift in the site at which food is consumed. 
I next divide the housing expenditure variable into rental and mortgage expenditures. Rental expenditures have the advantage that they may more appropriately reflect the service flow from the house, particularly if women are living in houses where much of the mortgage has been paid down. In fact, while the estimates are not very precise, most of the housing expenditure effect appears to be arising through changes in rental expenditures. This suggests that women are truly improving the quality of their living situation as AFDC benefits rise.

The final row extends the analysis of housing expenditures by assessing whether AFDC generosity affects the likelihood of moving when one becomes a single mother. The coefficient is from a probit regression, and the implied marginal probability is presented in the second column. ${ }^{31}$ There is a positive coefficient on AFDC benefits which is marginally significant. It implies that each $\$ 1000$ of AFDC benefits raises the likelihood of moving by 4.3 percentage points. This is roughly a $12 \%$ rise in the likelihood of moving for women who become single mothers. Taken further confirms that one role played by AFDC is to allow single mothers to improve their living situations, which is consistent with the conclusion of Ellwood and Bane (1985).

\section{Extension: Sub-Populations}

In Table 6, I explore how this result varies across the different types of transitions to single motherhood. I begin by dividing the sample into those who become single mothers through marital dissolution, and those who become single mothers through child-bearing. The overall effect on food and housing is approximately twice as large for the former group. For this group, the implied fall in consumption at zero AFDC benefits is quite large ( $\$ 1925$ dollars), and represents $34 \%$ of this

\footnotetext{
${ }^{31}$ The set of controls in the regression is limited in the same manner as for the selection probits described earlier.
} 
group's baseline pre-dissolution consumption. For those who have unmarried births, the reduced form effect is smaller and is not significant, although the standard error is large.

Dividing consumption into its components, it appears that most of the effect of AFDC on the marital dissolution sample is coming through housing expenditures, not through food. In fact, for food the estimated effect is larger for the unmarried births sample; but for this sample there is no effect whatsoever on housing expenditures.

In the next row of the Table, I reduce the sample further to those who had marital dissolution and are now family heads. This removes noise in the consumption data by allowing me to measure consumption for the AFDC-eligible unit only. And, as discussed earlier, this allows for a more precise control for composition change by using a sample that is undergoing a common transition. In fact, for this sample the effects are all somewhat stronger than in the first row: the implied fall at zero benefits is $44 \%$ of the baseline consumption before dissolution for this population. The difference between the first and third rows arises from a stronger food expenditure effect for those who are now family heads; for this population, both components of consumption rise significantly. Thus, to summarize, it appears that the effect of AFDC is stronger for those who become single heads through marital dissolution, and this is primarily because there is an effect on housing consumption which is not present for those who enter this state through child-bearing. In both groups, however, there is a sizeable effect on food expenditure changes.

This finding for housing expenditures is striking and bears on an important normative question that is raised by the analysis. A number of critics of the AFDC program have suggested that the fact that single mothers may use their benefits to move out of the family home and set up their own residence is a cost, not a benefit, of the program. This is because, for example, it may rob the new child of a stable home atmosphere that can serve as a role model. I have ignored this 
point in the analysis thus far, considering the woman as optimizing over her opportunity set; this argument implies that the social welfare maximum may involve constraining the woman's choice set.

Presumably, however, this argument applies more strongly to single women who have children, as opposed to women who are divorced and may need to find a new place to live. But the evidence presented here suggests that it is only for divorced women that AFDC generosity affects spending on housing. ${ }^{32}$ This suggests that there is less need for concern over the potentially pernicious effects of AFDC generosity in encouraging young never married women to set up their own residences.

Finally, as noted earlier, an alternative means of dealing with the fact that family composition is changing is to hold the composition of the family constant. That is, I can redefine the "family" to include all former members of the family in which the woman resided in period $t-1$. By adding together the period $t$ consumption of all individuals who resided together at $t-1$, I avoid potential biases arising from my focus just on those who reside with the woman in period $t$.

Of the 1320 women who become single mothers in these data, in roughly $1 / 4$ of the cases (317) there is data on the consumption change of other families who resided with the women in period $t-1$. In the next to last row of Table 6 , I show the basic results for the treatment families only for this subsample. The results are slightly stronger than the full sample findings from Table 2 , but they are similar to the results for heads, and most of this sample is heads. In the next row, I use the total consumption in period $\mathrm{t}$ for all families that splitoff from the woman's household in period

\footnotetext{
${ }^{32}$ Indeed, when I rerun the moving equations from Table 5 separately for marital dissolution and for single childbearing, I find that the effect is much stronger for the marital dissolution sample, which is consistent with the housing expenditure results; however, the estimate is insignificant for this group.
} 
t-1. The coefficient estimates are almost identical, although the standard errors are somewhat higher, making precise inferences difficult. Interestingly, the mean consumption change is much smaller overall when we add in the consumption of splitoffs, and is wrong signed for the two components. ${ }^{33}$ The wrong signed components presumably reflect the fact that economies of scale considerations dictate larger spending on average when households split than when they are together.

\section{Part V: Conclusions}

The current system of providing cash welfare to single mothers and their children is likely to be a contentious source of debate for the foreseeable future. Despite a lack of strong evidence of disincentive effects, the intuitive case that more generous AFDC should lead to lower levels of labor supply and family dissolution provides strong motivation for reform of the system. The point of this paper is to provide some evidence of the benefits of this program that can be weighed in the reform calculus. My findings suggest that AFDC plays an important role in smoothing the consumption of women who become single mothers. Clearly, consumption expenditures is only one proxy for well being, and there are other measures that should be considered in future work on this topic. But these best available proxies from the PSID suggest that reducing this safety net will lead to a serious reduction in the standard of living of women who become single mothers and their families.

An important caveat to this exercise, however, is that I have only considered variations within the existing structure of the cash welfare system. If this system were abolished altogether, or changed in some other dramatic fashion (such as through time limits or binding "work for welfare"

\footnotetext{
${ }^{33}$ Note that the predictions for the components need not add to the prediction for the total of consumption, if the control variables have very different effects on food and housing expenditure.
} 
requirements), it could cause a shift in the nature of private insurance mechanisms which would mitigate the consumption smoothing costs of reduced welfare generosity. As states experiment with such radical changes to their welfare systems, it would behoove administrators to collect information not only on labor supply and family structure but on measures of material well being which can be used to evaluate the insurance impacts of changing the structure of the welfare system. 


\section{References}

Angrist, Joshua (1990). "Lifetime Earnings and the Vietnam Era Draft Lottery: Evidence from Social Security Administrative Records," American Economic Review 80, 313-336.

Blank, Rebecca M., and Patricia Ruggles, "Why Do Women Use AFDC \& Food Stamps: The Dynamics of Eligibility vs. Participation," NBER Working Paper No. 4429, August 1993.

Currie, Janet, and Nancy Cole (1993). "Welfare and Child Health: The Link Between AFDC Participation and Birth Weight," American Economic Review, 83.

Currie, Janet, and Jonathan Gruber (1996a). "Saving Babies: The Efficacy and Cost of Recent Expansions of Medicaid Eligibility for Pregnant Women," Journal of Political Economy, forthcoming

Currie, Janet, and Jonathan Gruber (1996b). "Health Insurance Eligibility, Utilization of Medical Care, and Child Health," Quarterly Journal of Economics, 111, 431-466.

Danziger, Sheldon, Robert Haveman and Robert Plotnick (1981). "How Income Transfers Affect Work, Savings, and the Income Distribution: A Critical Review," Journal of Economic Literature, 19:975-1028.

Economic Report of the President, 1984.

Edin, Kathryn J. (1995). "The Myths of Dependence and Self-Sufficiency: Women, Welfare, and Low-Wage Work," Focus, Winter, p. 1-9.

Ellwood, David, and Mary Jo Bane (1985). "The Impact of AFDC on Family Structure and Living Arrangements," in Ronald Ehrenberg, Ed., Research in Labor Economics, Vol 8. Greenwich, CT: JAI Press.

Fraker, Thomas M., Alberto P. Martini, and James C. Ohls (1995). "The Effect of Food Stamp Cashout on Food Expenditures," Journal of Human Resources, 30.

Gruber, Jonathan (1994). "The Consumption Smoothing Benefits of Unemployment Insurance," American Economic Review, forthcoming.

Hoynes, Hilary W. (1995). "Does Welfare Play and Role in Female Headship Decisions?," NBER Working Paper \#5149.

Manser, Marilyn E. (1992). "Estimates of Cash-Equivalent Values from a Flexible Demand System for the U.S.". U.S. Department of Labor, Bureau of Labor Statistics Office of Research and Evaluation, Working Paper $\$ 235$.

Moffitt, Robert (1983). "An Economic Model of Welfare Stigma," American Economic Review, 73:1023-1035. 
Moffitt, Robert (1986). "Work Incentives in Transfer Programs (Revisited): A Study of the AFDC Program, " in Ronald Ehrenberg, Ed., Research in Labor Economics, Volume 8. Greenwich, CT: JAI Press.

Moffitt, Robert (1989). "Estimating the Value of an In-Kind Transfer: The Case of Food Stamps," Econometrica, 57:385-409.

Moffitt, Robert (1992). "Incentive Effects of the U.S. Welfare System: A Review," Journal of Economic Literature, 30:1-61.

Moffitt, Robert (1994). "Welfare Effects on Female Headship with Area Effects," Journal of Human Resources, 29: 621-636.

Moffitt, Robert, and Michael S. Rendall (1993). "Using the PSID Relationship File to Construct Measures of Female Family Headship". Mimeo, Brown University.

Murray, Charles (1984). Losing Ground. New York: Basic Books.

Olasky, Marving (1992). The Tragedy of American Compassion. Lanham, MD: Regenery.

Olsen, Edgar O., and David M. Barton (1983). "The Benefits and Costs of Public Housing in New York City," Journal of Public Economics, 20, 299-332.

Pollack, Harold (1994). Informal Transfers within Families. Ph.D. Thesis, John F. Kennedy School of Government, Harvard University.

Powers, Elizabeth (1996). "Does Means-Testing Welfare Discourage Saving? Evidence from the National Longitudinal Survey of Women." Mimeo, Federal Reserve Bank of Cleveland.

Reeder, William J. (1985). "The Benefits and Costs of the Section 8 Existing Housing Program," Journal of Public Economics, 26, 349-377.

Rosenzweig, Mark, and Kenneth I. Wolpin (1994). "Parental and Public Transfers to Young Women and Their Children," American Economic Review, 84, 1195-1212.

Scheoni, Robert (1994). "Does Aid to Families with Dependent Children Displace Familial Assistance?". Mimeo, RAND Corporation.

Schwab, Robert M. (1985). "The Benefits of In-Kind Government Programs," Journal of Public Economics, 27, 195-210.

Smeeding, Timothy, and Marilyn Moon (1980). "Valuing Government Expenditures: The Case of Medical Care Transfers," Review of Income and Wealth, 26:305-324.

U.S. House of Representatives, Committee on Ways and Means (1993). Overview of Entitlement 
Programs: 1993 Green Book. Washington, D.C.: U.S. Government Printing Office.

Wolfe, Barbara, and Robert Moffitt (1991). "A New Index to Value In-Kind Benefits," Review of Income and Wealth, 37: 387-408.

Zeldes, Stephen P. (1989). "Consumption and Liquidity Constraints: An Empirical Investigation." Journal of Political Economy, 97, 305-346. 


\section{Appendix - Option Value and Bias to 2SLS Estimate}

In this appendix I explore the potential bias to the 2SLS estimate of the consumption smoothing impact of AFDC arising from an option value effect. I do so within the framework of a simple two observation example, which allows me to compute the $2 S L S$ estimate as a Wald estimator, or a ratio of the reduced form and first stage effects (Angrist, 1991).

In this simplified example, consumption is modelled by:

$$
C=K+\beta^{*} \alpha^{*} P B+\beta^{*}(1-\alpha)^{*} x^{*} P B
$$

where $\mathrm{C}$ is consumption

$K$ is a constant interest)

$\beta$ is the true consumption effect of AFDC receipt (the structural parameter of

$\alpha$ is the fraction of single mothers receiving AFDC

$\mathrm{PB}$ is potential benefits

$X$ is the option value $(0<x<1)$

The first term is some constant which is independent of the AFDC system. The second is the effect of AFDC on recipients, and the third is the effect on non-recipients, which is non-zero only if there is some option value.

Differentiating this equation with respect to potential benefits:

(2) $\delta \mathrm{C} / \delta \mathrm{PB}=\beta *[\delta \alpha / \delta \mathrm{PB} * \mathrm{~PB} *(1-\mathrm{x})+\alpha+(1-\alpha) \mathrm{x}]$

Where $\delta \alpha / \delta \mathrm{PB}$ is the marginal takeup effect of increases in potential benefits (the increase beyond the automatic rise in benefits received at a given level of takeup). We can compute the 2SLS coefficient of interest as $\delta \mathrm{C} / \delta \mathrm{PB} / \delta \mathrm{BEN} / \delta \mathrm{PB}$, where $\mathrm{BEN}$ is benefits received. BEN is determined according to:

(3) BEN $=\alpha^{*} P B$, so that

(4) $\delta \mathrm{BEN} / \delta \mathrm{PB}=\delta \alpha / \delta \mathrm{PB} * \mathrm{~PB}+\alpha$

Combining these equations, we obtain a 2 SLS coefficient of:

(5) $\beta^{\prime}=\beta^{*}\left[\delta \alpha / \delta \mathrm{PB}^{*} \mathrm{~PB} *(1-\mathrm{x})+\alpha+(1-\alpha) \mathrm{x}\right]$

$$
\delta \alpha / \delta \mathrm{PB} * \mathrm{~PB}+\alpha
$$

The second term is the bias to our parameter of interest, $\beta$. The sign is indeterminate. If $\mathrm{x}=0, \beta^{\prime}=\beta$; there is no bias if there is no option value, and the 2SLS estimate is appropriate. If $\mathrm{x}>0$, and $\delta \alpha / \delta \mathrm{PB}=0$ (no marginal takeup effect), then the bias is clearly upwards. If $\delta \alpha / \delta \mathrm{PB}$ $>0$ as well, however, the bias is indeterminate, although it will still be upwards except when $\delta \alpha / \delta \mathrm{PB}$ is very large. 
Given the PSID data available, I can compute the parameters that enter into equation (5), except for $x$ (the unobserved option value). At the sample mean, PB is $3874, \alpha$ is 0.26 , and $\delta \alpha / \delta \mathrm{PB}$ is $0.00001 .^{34}$ For these values, (5) yields:

(6) $\beta^{\prime}=\beta *\left[0.06^{*}(1-x)+.26+.74^{*} x\right] /[0.06+.26]>\beta$

This expression is always greater than $\beta$, indicating that the bias is clearly upwards in this case. For an option value of 0.1 (being eligible for $\$ 100$ in AFDC is equivalent to receiving $\$ 10$ of AFDC), for example, there is an upward bias of $24 \%$ to the 2 SLS estimate.

${ }^{34} \alpha$ is computed by simply taking the sample mean of benefits received/maximum payment for the treatment group; the maximum value of this ratio is set to one for the few outlying observations which report more AFDC benefits than potential entitlement. $\delta \alpha / \delta \mathrm{PB}$ is simply the first stage coefficient from equation (2), minus alpha, divided by the mean of potential benefits. 


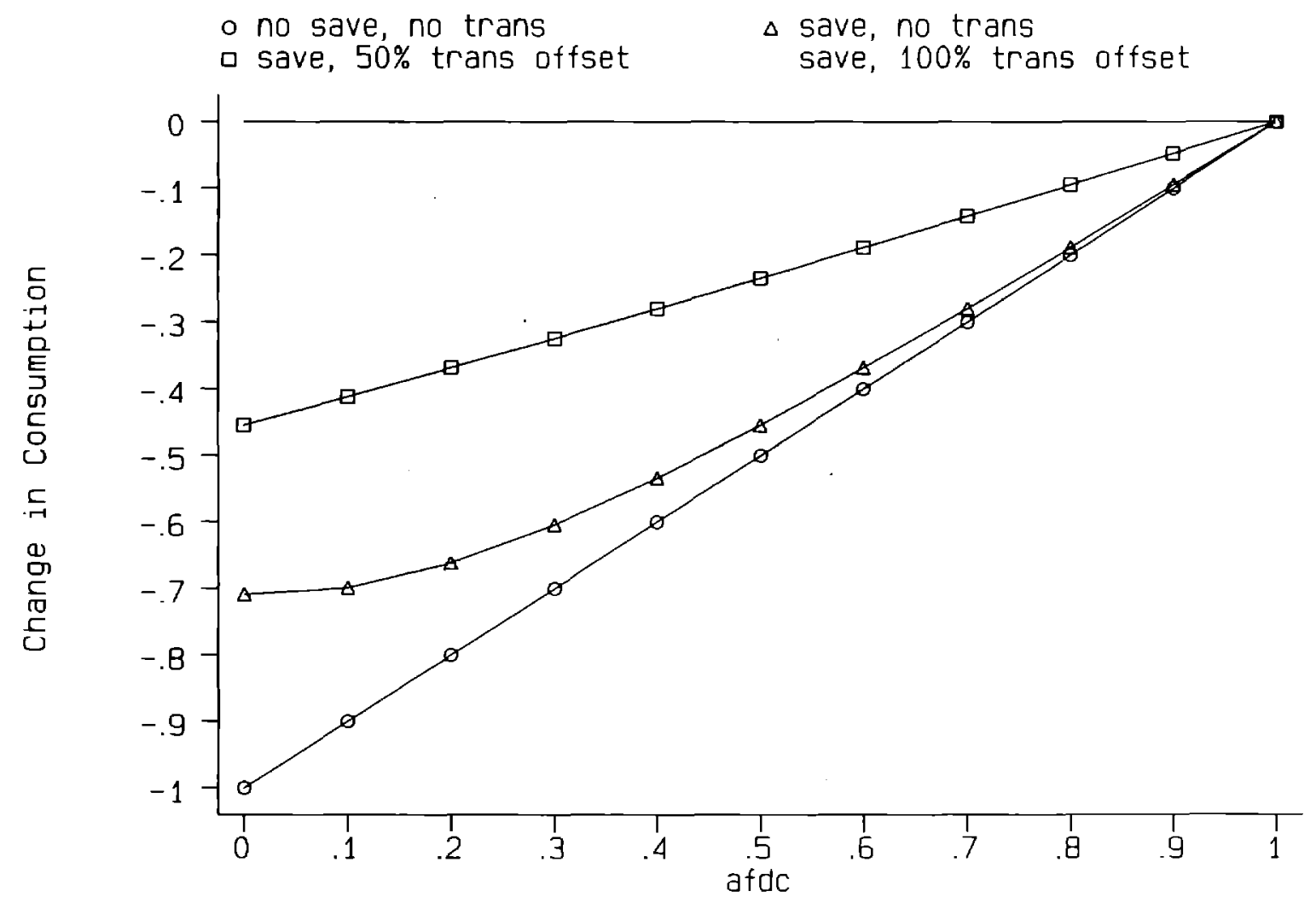

Figure 1: Consumption Smoothing Effects of AFDC 


\begin{tabular}{|c|c|c|}
\hline Variable & $\begin{array}{c}\text { Single Mother } \\
\text { Transitions }\end{array}$ & Control Group \\
\hline $\begin{array}{l}\text { Change in Food \& } \\
\text { Housing Expenditures }\end{array}$ & $\begin{array}{c}-184 \\
{[2435]} \\
\{5991\}\end{array}$ & $\begin{array}{c}8.88 \\
{[2528]} \\
\{6898\}\end{array}$ \\
\hline $\begin{array}{l}\text { Change in Food } \\
\text { Expenditures }\end{array}$ & $\begin{array}{c}-227 \\
{[1995]} \\
\{4035\}\end{array}$ & $\begin{array}{c}-70 \\
{[1929]} \\
\{4482\}\end{array}$ \\
\hline $\begin{array}{l}\text { Change in Housing } \\
\text { Expenditures }\end{array}$ & $\begin{array}{c}43.0 \\
{[1303]} \\
\{1956\}\end{array}$ & $\begin{array}{c}78.9 \\
{[1544]} \\
\{2416\}\end{array}$ \\
\hline Move Residence & 0.372 & 0.250 \\
\hline AFDC Maximum Payment & $\begin{array}{c}3874 \\
{[2185]}\end{array}$ & $\begin{array}{c}4054 \\
{[2133]}\end{array}$ \\
\hline White & 0.276 & 0.565 \\
\hline Black & 0.630 & 0.316 \\
\hline Age & $\begin{array}{c}25.5 \\
{[9.27]}\end{array}$ & $\begin{array}{c}30.8 \\
{[12.9]}\end{array}$ \\
\hline $\begin{array}{c}\text { Age of Household } \\
\text { Head }\end{array}$ & $\begin{array}{c}37.2 \\
{[12.3]}\end{array}$ & $\begin{array}{c}39.6 \\
{[13.1]}\end{array}$ \\
\hline Head is HS Dropout & 0.539 & 0.371 \\
\hline Head is HS Grad & 0.202 & 0.202 \\
\hline Head has some College & 0.214 & 0.284 \\
\hline Head is College Grad & 0.045 & 0.142 \\
\hline AFDC Unit Size & $\begin{array}{c}2.65 \\
{[1.18]}\end{array}$ & $\begin{array}{l}2.58 \\
{[1.16]}\end{array}$ \\
\hline Welfare Received & $\begin{array}{c}1371 \\
{[2646]}\end{array}$ & $\begin{array}{c}350 \\
{[1515]}\end{array}$ \\
\hline Unemployment Rate & $\begin{array}{c}0.071 \\
{[0.020]}\end{array}$ & $\begin{array}{c}0.069 \\
{[0.020]}\end{array}$ \\
\hline $\begin{array}{l}\text { Log of Personal Inc } \\
\text { per capita }\end{array}$ & $\begin{array}{c}2.022 \\
{[0.437]}\end{array}$ & $\begin{array}{c}2.067 \\
{[0.426]}\end{array}$ \\
\hline Number of Obs & 1320 & 50841 \\
\hline
\end{tabular}

Notes: Standard Deviations in square brackets; lagged values in curly brackets. All dollar figures are in real 1984 dollars. Control group is those remain non-single mothers over 2 periods. 


\begin{tabular}{|c|c|c|c|}
\hline & Food + Housing & Food & Housing \\
\hline AFDC Maximum & $\begin{array}{c}0.302 \\
(0.113)\end{array}$ & $\begin{array}{r}0.177 \\
(0.091)\end{array}$ & $\begin{array}{c}0.124 \\
(0.066)\end{array}$ \\
\hline White & $\begin{array}{r}-118 \\
(372)\end{array}$ & $\begin{array}{l}-305 \\
(301)\end{array}$ & $\begin{array}{c}187 \\
(217)\end{array}$ \\
\hline Black & $\begin{array}{c}-36 \\
(359)\end{array}$ & $\begin{array}{l}-125 \\
(300)\end{array}$ & $\begin{array}{r}89.2 \\
(209)\end{array}$ \\
\hline Age & $\begin{array}{l}-12.4 \\
(11.0)\end{array}$ & $\begin{array}{l}-11.3 \\
(8.88)\end{array}$ & $\begin{array}{l}-1.16 \\
(6.41)\end{array}$ \\
\hline Head's Age & $\begin{array}{c}5.14 \\
(7.96)\end{array}$ & $\begin{array}{l}4.49 \\
(6.43)\end{array}$ & $\begin{array}{l}0.65 \\
(4.64)\end{array}$ \\
\hline $\begin{array}{c}\text { Head is } \\
\text { HS Dropout }\end{array}$ & $\begin{array}{l}1957 \\
(323)\end{array}$ & $\begin{array}{l}-133 \\
(261)\end{array}$ & $\begin{array}{r}328 \\
(188)\end{array}$ \\
\hline $\begin{array}{l}\text { Head is } \\
\text { HS Grad }\end{array}$ & $\begin{array}{c}122 \\
(335)\end{array}$ & $\begin{array}{l}-94.8 \\
(271)\end{array}$ & $\begin{array}{c}216 \\
(1895\end{array}$ \\
\hline $\begin{array}{c}\text { Head has } \\
\text { some College }\end{array}$ & $\begin{array}{l}-13.9 \\
(334)\end{array}$ & $\begin{array}{l}-261 \\
(270)\end{array}$ & $\begin{array}{r}247 \\
(195)\end{array}$ \\
\hline $\begin{array}{l}\text { Marital Dissolution } \\
\text { vs. Child-Bearing }\end{array}$ & $\begin{array}{c}323 \\
(255)\end{array}$ & $\begin{array}{c}225 \\
(206)\end{array}$ & $\begin{array}{r}98.3 \\
(148)\end{array}$ \\
\hline $\begin{array}{l}\text { Change in Family } \\
\text { Consumption Needs }\end{array}$ & $\begin{array}{c}0.360 \\
(0.080)\end{array}$ & $\begin{array}{c}0.378 \\
(0.064)\end{array}$ & $\begin{array}{l}-0.019 \\
(0.046)\end{array}$ \\
\hline $\begin{array}{c}\text { Unemployment } \\
\text { Rate }\end{array}$ & $\begin{array}{l}-13800 \\
(10955)\end{array}$ & $\begin{array}{l}-10845 \\
(8858)\end{array}$ & $\begin{array}{l}-2954 \\
(6385)\end{array}$ \\
\hline Log of Personal Inc & $\begin{array}{r}-3774 \\
(4369)\end{array}$ & $\begin{array}{l}-4301 \\
(3502)\end{array}$ & $\begin{array}{l}528 \\
(2547)\end{array}$ \\
\hline $\begin{array}{l}\text { Implied Consumption } \\
\text { Change at } 0 \text { Benefits }\end{array}$ & -1353 & -914 & -439 \\
\hline 2SLS Estimate & $\begin{array}{c}0.946 \\
(0.422)\end{array}$ & $\begin{array}{c}0.556 \\
(0.354)\end{array}$ & $\begin{array}{l}0.390 \\
(0.251)\end{array}$ \\
\hline Number of Obs & 1320 & 1320 & 1320 \\
\hline
\end{tabular}

Notes: Standard errors in parentheses. Regressions also control for fixed effects for AFDC unit size, family size, change in family size, state and year, and for state-specific time trends. 2SLS estimate is from a separate estimation of the system of equations (2) in the text. 


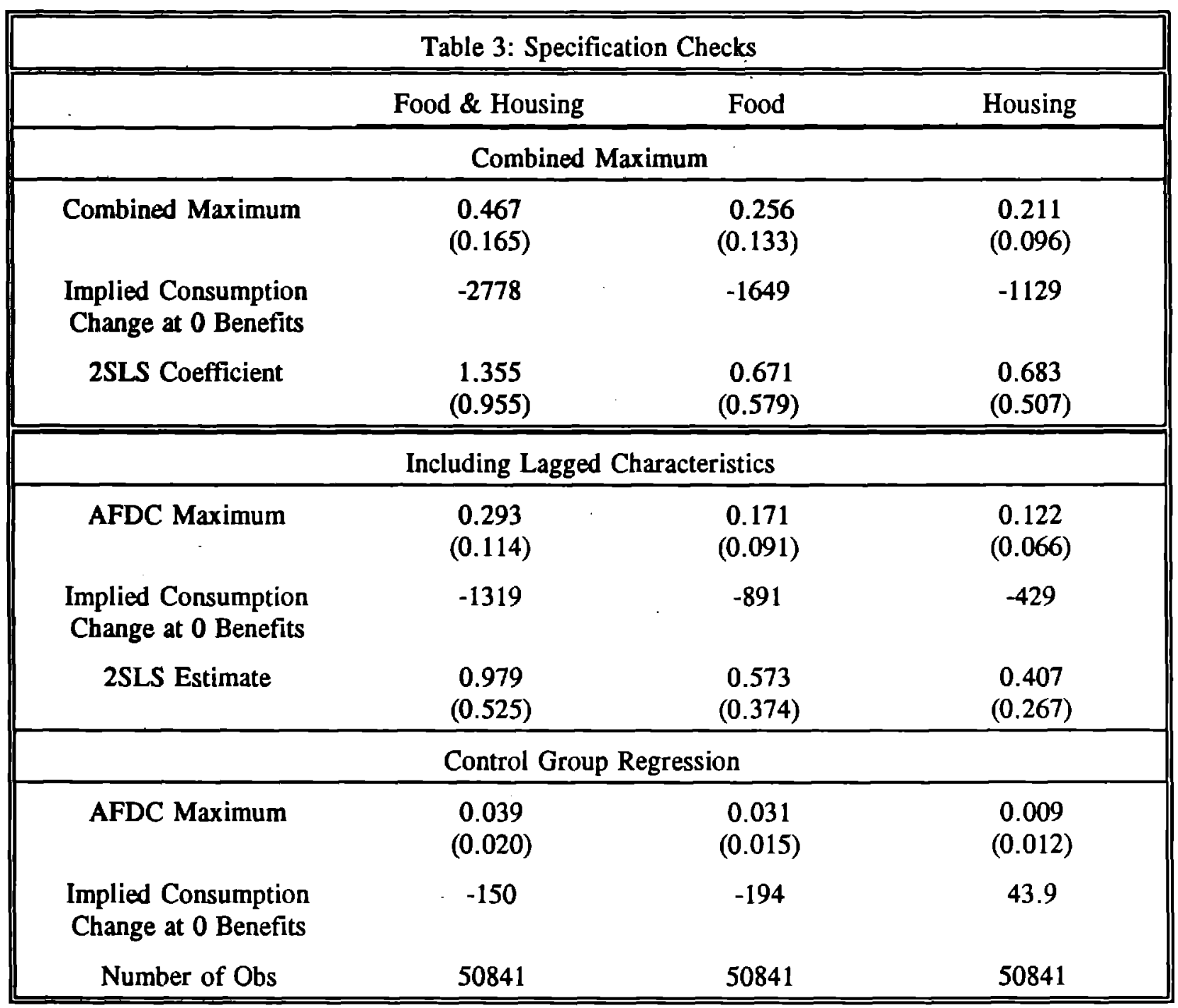

Notes: Standard errors in parentheses. Regressions also control for fixed effects for AFDC unit size, family size, change in family size, state and year, and for state-specific time trends. 2SLS estimate is from a separate estimation of the system of equations (2) in the text. 


\begin{tabular}{|c|c|c|}
\hline \multicolumn{3}{|c|}{ Table 4: Selection Probits } \\
\hline & $\begin{array}{l}\text { Transition through } \\
\text { Dissolution }\end{array}$ & $\begin{array}{l}\text { Transition through } \\
\text { Child-Bearing }\end{array}$ \\
\hline $\begin{array}{l}\text { AFDC Maximum } \\
(/ 10000)\end{array}$ & $\begin{array}{c}0.114 \\
(0.289)\end{array}$ & $\begin{array}{r}-0.695 \\
(0.611)\end{array}$ \\
\hline White & $\begin{array}{r}-0.118 \\
(0.093)\end{array}$ & $\begin{array}{r}-0.301 \\
(0.113)\end{array}$ \\
\hline Black & $\begin{array}{c}0.133 \\
(0.093)\end{array}$ & $\begin{array}{c}0.350 \\
(0.109)\end{array}$ \\
\hline Age & $\begin{array}{l}-0.002 \\
(0.002)\end{array}$ & $\begin{array}{l}-0.010 \\
(0.003)\end{array}$ \\
\hline $\begin{array}{l}\text { Head is } \\
\text { HS Dropout }\end{array}$ & $\begin{array}{c}0.349 \\
(0.076)\end{array}$ & $\begin{array}{c}0.319 \\
(0.088)\end{array}$ \\
\hline $\begin{array}{l}\text { Head is } \\
\text { HS Grad }\end{array}$ & $\begin{array}{r}0.296 \\
(0.078)\end{array}$ & $\begin{array}{c}0.267 \\
(0.094)\end{array}$ \\
\hline $\begin{array}{l}\text { Head has } \\
\text { some College }\end{array}$ & $\begin{array}{r}0.288 \\
(0.076)\end{array}$ & $\begin{array}{c}0.071 \\
(0.094)\end{array}$ \\
\hline $\begin{array}{l}\text { Unemployment } \\
\text { Rate }\end{array}$ & $\begin{array}{l}-0.621 \\
(3.002)\end{array}$ & $\begin{array}{c}0.201 \\
(3.127)\end{array}$ \\
\hline Log of Personal Inc & $\begin{array}{r}-1.161 \\
(1.170)\end{array}$ & $\begin{array}{l}-0.139 \\
(1.323)\end{array}$ \\
\hline $\begin{array}{c}\text { Effect of } \$ 1000 \\
\text { AFDC Benefit Increase }\end{array}$ & 0.00069 & -0.00549 \\
\hline Mean of Depdendent Var. & 0.0227 & 0.0423 \\
\hline Number of Obs & 21851 & 16294 \\
\hline
\end{tabular}

Notes: Standard errors in parentheses. Regressions also control for fixed effects for AFDC unit size, state and year, and for state-specific time trends. Effect of $\$ 1000$ AFDC Benefit Increase is change in implied marginal probability from raising AFDC benefits by $\$ 1000$, averaged across the relevant sample. 
Table 5: Extension: Types of Consumption

\begin{tabular}{|ccc|}
\hline \hline & Coefficient & $\begin{array}{c}\text { Implied Change } \\
\text { at 0 Benefits } \\
\text { (or marg. prob.) }\end{array}$ \\
\cline { 2 - 3 } Food Out & -0.021 & 85.1 \\
& $(0.034)$ & \\
Food at Home & 0.199 & -999 \\
Rent & $(0.084)$ & -294 \\
& 0.096 & \\
& $(0.064)$ & -145 \\
Mortgage & 0.028 & 4.26 \\
Likelihood of & $(0.056)$ & \\
Moving Probit & 0.134 & \\
(Coeff * 10) & $(0.071)$ & \\
\hline
\end{tabular}

Notes: Standard errors in parentheses. Regressions also control for fixed effects for AFDC unit size, family size, change in family size, state and year, and for state-specific time trends (except for final row, as described in text). Second column of contains implied effects at zero AFDC benefits or implied marginal probability from probit regression. 


\begin{tabular}{|c|c|c|c|c|c|c|}
\hline \multicolumn{7}{|c|}{ Table 6: Extension: Sub-Populations } \\
\hline & \multicolumn{2}{|c|}{ Food \& Housing } & \multicolumn{2}{|c|}{ Food } & \multicolumn{2}{|c|}{ Housing } \\
\hline & Coeff. & $\begin{array}{l}\text { Implied } \\
\text { Change }\end{array}$ & Coeff. & $\begin{array}{l}\text { Implied } \\
\text { Change }\end{array}$ & Coeff. & $\begin{array}{l}\text { Implied } \\
\text { Change }\end{array}$ \\
\hline $\begin{array}{c}\text { Marital } \\
\text { Dissolution }\end{array}$ & $\begin{array}{c}0.377 \\
(0.159)\end{array}$ & -1925 & $\begin{array}{c}0.111 \\
(0.114)\end{array}$ & -791 & $\begin{array}{c}0.266 \\
(0.106)\end{array}$ & -1135 \\
\hline $\begin{array}{l}\text { Unmarried } \\
\text { Births }\end{array}$ & $\begin{array}{c}0.165 \\
(0.269)\end{array}$ & -708 & $\begin{array}{c}0.163 \\
(0.236)\end{array}$ & -721 & $\begin{array}{r}0.009 \\
(0.138)\end{array}$ & -8.9 \\
\hline $\begin{array}{l}\text { Dissolution } \\
\text { to Heads }\end{array}$ & $\begin{array}{c}0.465 \\
(0.156)\end{array}$ & -2450 & $\begin{array}{c}0.199 \\
(0.113)\end{array}$ & -1309 & $\begin{array}{c}0.266 \\
(0.103)\end{array}$ & -1140 \\
\hline $\begin{array}{l}\text { Splitoffs in } \\
\text { PSID (elig.) }\end{array}$ & $\begin{array}{c}0.431 \\
(0.329)\end{array}$ & -2136 & $\begin{array}{c}0.290 \\
(0.260)\end{array}$ & -2322 & $\begin{array}{c}0.141 \\
(0.191)\end{array}$ & -616 \\
\hline $\begin{array}{c}\text { Eligibles }+ \\
\text { Splitoffs }\end{array}$ & $\begin{array}{c}0.457 \\
(0.428)\end{array}$ & -674 & $\begin{array}{c}0.294 \\
(0.350)\end{array}$ & 692 & $\begin{array}{c}0.163 \\
(0.217)\end{array}$ & 1251 \\
\hline
\end{tabular}

Notes: Standard errors in parentheses. Regressions also control for fixed effects for AFDC unit size, family size, change in family size, state and year, and for state-specific time trends. Second column of each panel contains implied effects at zero AFDC benefits. 